\title{
International carbon trade with constrained allowance choices: Results from the STACO model
}

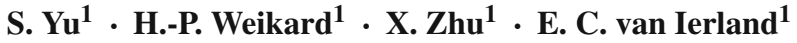

Published online: 9 February 2016

(C) The Author(s) 2016. This article is published with open access at Springerlink.com

\begin{abstract}
International carbon markets are advocated in order to involve more countries in an agreement for the mitigation of greenhouse gas emissions and to reduce the costs of mitigation. In this paper we develop a model where allowances are endogenously determined by each member of a carbon trade agreement, but with an exogenous constraint on the number of allowances per member. We use a global model to explore the incentives for regions to participate in such a carbon market and we examine its performance. To gain practical policy insights, we employ the STACO model, a numerically calibrated model with twelve world regions. Our results show that the stability and effectiveness of an international carbon market can be improved by imposing constraints on individual allowance choices compared to a carbon market without such constraints. Constraints on allowance choices reduce 'hot air' and increase global welfare and mitigation. When tightening the constraint 'broad but shallow' agreements are replaced by 'narrow but deep' ones. If the constraint is too tight, however, no stable carbon market exists.
\end{abstract}

Keywords International carbon trade - International climate agreements - Allowance choice $\cdot$ Carbon markets $\cdot$ STACO model

\section{Introduction}

Carbon emissions can be cost-efficiently reduced by means of carbon trade. The European Union Emission Trading Scheme (EU ETS) is an attempt to do this. Compared to a partial or regional carbon market, a global approach to carbon trade would engage all countries in emission mitigation. Moreover, inclusion of the major and low-cost emitters into the market could help to meet more ambitious mitigation targets and reduce abatement costs (Stern 2008; Behr et al. 2009; Flachsland et al. 2009). Yet, no global market for carbon has emerged so

\section{S. Yu}

shumin.yu@wur.nl

1 Environmental Economics and Natural Resources Group, Wageningen University, P.O. Box 8130, 6700 EW Wageningen, The Netherlands 
far. This can be explained by free-riding incentives to abstain from a global climate agreement (Barrett 1994). From the perspective of political efforts there are two approaches to a global emission trading system: the top-down approach based on government-to-government trading of emission allowances; and the bottom-up approach based on the linkage between regional emission trading systems (Stavins and Jaffe 2008; Behr et al. 2009; Flachsland et al. 2009). According to Flachsland et al. (2009), the top-down approach would generally cover a larger share of global emissions and is associated with larger mitigation efforts as compared to the bottom-up approach.

The possibility to meet an emission reduction target by means of a government-togovernment emission trading system was firstly established and specified by the Marrakesh Accords in 2001 based on the Kyoto Protocol. However, this trading system only includes the developed countries (listed in Annex I of the Kyoto Protocol). Given that growing shares of global emissions stem from emerging (non-Annex I) economies, like China and India, the effectiveness of a partial international trading system supported by the Marrakesh Accords and the Kyoto Protocol can be enhanced. As a project-based trading system, the Clean Development Mechanism (CDM) allows the Annex I countries to get tradable emission reduction credits when investing in emission-reduction projects in developing countries (UNFCCC 1998). A limitation of the CDM is that only the Annex I countries are committed to the Kyoto mitigation targets, whereas developing countries are not committed to any mitigation.

In a market for carbon emission allowances countries with relatively high abatement costs would be buyers and have incentives to join a carbon market as the market offers cheaper abatement options. Countries with relatively low abatement costs would be sellers and could gain from earning revenues. In a carbon market with unconstrained endogenous allowance choices, as studied by Helm (2003), the motivation to raise revenues from carbon trading results in excessive allowance choices, so-called 'hot-air'. Such a carbon market is then characterised by modest emission reductions. Moreover, the stability of a carbon market with open membership could be undermined by incentives for participation that stem from selling carbon emission allowances. Therefore, imposing a constraint on allowance choices might not only mitigate the hot-air effect but can also help to stabilise a carbon market by avoiding excessive participation of potential sellers. However, a constraint on allowance choices can also generate free-riding incentives because the improved global abatement resulting from limiting carbon emission allowances will increase the payoffs of non-signatories. It is therefore important to study how exogenous constraints on allowance choices change the incentives to participate in an international carbon market and its environmental effectiveness. We address this problem by modelling a top-down approach to an international carbon market where emission allowances are traded between governments.

Stevens and Rose (2002) studied a restricted carbon market with a constraint on the volume of carbon transactions, i.e. purchases and sales of emission allowances, and showed that abatement costs would be increased due to the carbon trade restrictions. Rehdanz and Tol (2005) analysed the impacts of regulation imposed on a bilateral carbon market. They assume that the carbon buying country will suffer higher damages from GHG emissions. Therefore, the carbon buying country can strategically and unilaterally set stricter abatement targets for its own emissions aiming to reduce its carbon allowance imports and limiting emission permits issued by the selling country. Their research shows that the regulation of the quantity of emission permits makes both countries worse off if the regulation adopted by the buying country is strict, as this reduces cost-savings from trade. Altamirano-Cabrera and Finus (2006) consider uniform emission reductions to define tradable quota. They study the impact of restricted carbon trade on the formation and efficiency of climate coalitions, but they do not consider allowance choices. Carbone et al. (2009) apply Helm's idea of 
a carbon market with endogenous allowance choices in a calibrated general equilibrium model. They analyse participation incentives and environmental effectiveness of international carbon trade agreements. In order to mitigate the hot-air effect Carbone et al. (2009) consider a setting where incumbent members of the carbon market may block entry of additional potential market participants, i.e. they only consider internal stability of the carbon market. In this paper we explore another option. While we maintain the idea of a carbon market with endogenous allowance choice, we use an open-membership model, in line with most currently existing international environmental agreements. In our model the hot-air effect is mitigated by constraining the allowance choice. The constraint is exogenous to our model. Hence, we consider it to be part of the agreement that is "on the table" ready to be signed.

We explore the incentives to join a carbon market in a two-stage non-cooperative game. In the first stage, regions decide simultaneously on their market participation. In the second stage signatories can choose their allowances and then trade. However the carbon trade agreement obliges all signatories to accept a constraint on their allowance choice that we model as a fraction of the business-as-usual (BAU) emissions. This setting is in line with the 'cap-and-trade' system of the EU ETS where caps were set relative to historical emission levels. BAU emission levels reflect historical emission levels, i.e. carbon emissions before any (unilateral) climate policies were adopted. Historical emission levels have also played a role as reference points in climate negotiations. Another reason for using BAU emissions levels as our base line is that, unlike Nash equilibrium levels, the BAU levels are exogenous to our model. Since it is still interesting to explore the setting when allowance constraints are tied to Nash-emissions levels, we provide results for this case in a sensitivity analysis. Generally we assume that non-signatories (or singletons) cannot participate in international carbon trade and, thus, they adopt their own carbon abatement policies. We examine cartel stability, i.e. we assume a single international carbon market which is stable if no signatory has an incentive to leave the market and no singleton has an incentive to join.

Intuitively, a carbon market with a constraint on allowance choices can be more effective in terms of emission reductions compared to an unconstrained market. We show this by employing the STACO model. STACO specifies business-as-usual emission paths and emission abatement costs and benefits functions for twelve heterogeneous world regions (Nagashima et al. 2011; Dellink et al. 2015). We use the model to identify stable carbon trade agreements. In particular we show that by tightening the constraint on allowance choices, the global mitigation level in a stable carbon market can be improved. Regarding the welfare effects, there are two main consequences. Firstly, by imposing a constraint on allowance choices, the benefits from global abatement can be increased, especially for the countries with relatively high marginal benefits from global abatement. Secondly, obviously, constraints on allowance choices reduce the supply of emission allowances in the carbon market. This will reduce hot air, drive up the carbon price and thereby reduce the benefits for carbon buyers. The revenues of carbon sellers could also be reduced as only a limited number of emission allowances can be sold. Furthermore, in our setting with asymmetric regions, individual welfare effects will differ per region due to the differences in marginal abatement costs and benefits.

The main idea of our paper is to investigate the impact of allowance choice constraints on participation incentives in a carbon market. The impact of the constraint is analysed by varying the level of the constraint parameter in our simulation analysis. We do not make a claim about which level of the constraint parameter would be chosen in the pre-negotiations to a trade agreement, i.e. we are not endogenising the constraint. In our approach the optimal level (in terms of global welfare) of the constraint is identified from numerical results from the STACO model. 
The paper is structured as follows. Section 2 describes our two-stage game of the formation of an international carbon market. In Sect. 3, we introduce the model with and without allowance choice constraints and we analyse the two-stage game by backward induction. The numerical analysis is implemented, and the results are presented and discussed in Sect. 4. The final section summarizes the main findings and discusses policy implications.

\section{Formation of an international emission trade agreement}

A standard two-stage coalition formation game is applied to study an international carbon market with heterogeneous regions. Each region is characterised by its abatement cost and benefit functions. The set of all regions is denoted by $N$. An individual region is indexed by $j$ with $j=1, \ldots, n$.

At stage 1, a membership game is played. All regions $j \in N$ simultaneously and noncooperatively choose whether or not to join a proposed carbon market. The choice set is defined as $\sigma_{j}=\{0,1\}$. If $\sigma_{j}=1$, then $j$ joins the market. If $\sigma_{j}=0$, then $j$ does not join and remains a singleton. Countries decide upon their membership by anticipating the welfare impacts of the allowance choices and the ultimate abatement level. We refer to the set of regions who join the market as traders $T$.

At stage 2, with a given set of traders $T$, every trader $j \in T$ chooses initial allowances, denoted by $\omega_{j}$, subject to a constraint and chooses abatement, denoted by $q_{j}$, depending on carbon trade. The constraint specifies the maximum level of allowances that each market participant can choose, denoted by $\omega_{j}^{\max }$. Specifically, the individual maximum allowances $\omega_{j}^{\max }$ are a fraction of the BAU emissions $\bar{e}_{j}(j \in T)$ such that $\omega_{j}^{\max }=\alpha \bar{e}_{j}$. In our model the parameter $\alpha \in[0,1]$ is the same for all carbon traders, but the maximum allowance choices $\omega_{j}^{\max }(j \in T)$ are different across traders since their BAU emissions $\bar{e}_{j}$ differ. As the mitigation target becomes stricter, the value of $\alpha$ decreases. The strictest possible constraint, $\alpha=0$, refers to a carbon-free economy. However, in our numerical simulations we do not consider constraints on allowance choices that are stricter than what the social optimum requires. In fact, our results from the STACO model in Sect. 4 show that no stable carbon market can be found when the constraint parameter is lower than 0.74 (see Table 3 in Sect. 4.2).

Following Helm's (2003) endogenous allowance choice model, each trade participant determines its best response allowance choice and after-trade abatement by solving the following problem:

$$
\max _{\omega_{j}, q_{j}} \pi_{j}=B_{j}\left(\sum_{j \in T} \bar{e}_{j}-\omega+\sum_{j \in N-T} q_{j}\right)-C_{j}\left(q_{j}\right)+p(\omega) \cdot\left(\omega_{j}-\left(\bar{e}_{j}-q_{j}\right)\right), \quad j \in T,
$$

subject to

$$
\begin{aligned}
0 & \leq \omega_{j} \leq \alpha \bar{e}_{j}, \quad \text { with } \alpha \in[0,1], \\
q_{j} & \geq 0 .
\end{aligned}
$$

The global abatement level is $q=\sum_{j \in T} \bar{e}_{j}-\omega+\sum_{j \in N-T} q_{j}$. In the objective function (Eq. 1), the total allowances are $\omega \equiv \sum_{j \in T} \omega_{j}$, which also represents the total emissions in the carbon market $T$. The carbon price is a function of emission allowances $\omega$ in the carbon market, denoted by $p(\omega)$ with $p^{\prime}(\omega) \leq 0$. Carbon price $p(\omega)$ is uniform for all trade participants. In line with the functional forms in the STACO model, we assume abatement benefits $B_{j}(q)$ that are linear in the total abatement with $B_{j}^{\prime}(q)>0$ and $B_{j}^{\prime \prime}(q)=0$. Abatement costs $C_{j}\left(q_{j}\right)$ are strictly convex in individual abatement with $C_{j}^{\prime}\left(q_{j}\right)>0$ and 
$C_{j}^{\prime \prime}\left(q_{j}\right)>0$. Emissions are denoted by $e_{j}=\bar{e}_{j}-q_{j}$ corresponding to the abatement level $q_{j}$. Note that the functional forms of $B_{j}(q)$ and $C_{j}\left(q_{j}\right)$ result in a concave net benefit function $B_{j}(q)-C_{j}\left(q_{j}\right)$, which assures that the optimal solution to the problem (1) is uniquely determined.

At this second stage, the non-traders $j \notin T$ choose their optimal mitigation level by solving

$$
\max _{q_{j}} \pi_{j}\left(q_{j}\right)=B_{j}(q)-C_{j}\left(q_{j}\right), \quad j \notin T .
$$

Because of the linear form of the abatement benefits function, singletons have a dominant strategy implying that the abatement level of any singleton is not influenced by the carbon market.

\section{Model and the theoretical analysis}

In this section we describe the sub-game perfect Nash equilibria (SPNE) of the game using backward induction.

\section{Stage 2: Equilibrium choices of allowances and abatement}

At the second stage, given the set of trade participants $T$ and a constraint $\omega_{j} \leq \alpha \bar{e}_{j}$ on individual allowance choices, the initial emission allowances and the after-trade abatement levels are chosen. The maximisation problem (1) gives the following Lagrangian function:

$$
L\left(\omega_{j} ; q_{j} ; \gamma_{j}\right)=\pi_{j}+\gamma_{j}\left(\alpha \bar{e}_{j}-\omega_{j}\right), \quad j \in T .
$$

In (3) $\gamma_{j}$ is the Lagrangian multiplier for individual emission allowance choices. By taking the derivatives of Eq. (3), the first order conditions for $\omega_{j}, q_{j}$ and $\gamma_{j}$ are derived as follows:

$$
\begin{gathered}
\frac{\partial L}{\partial \omega_{j}}=\frac{\partial \pi_{j}}{\partial \omega_{j}}-\gamma_{j}=p^{\prime}\left(\omega^{*}\right)\left(\omega_{j}^{*}-e_{j}^{*}\right)+p-B_{j}^{\prime}-\gamma_{j}=0 \\
\frac{\partial L}{\partial q_{j}}=-C_{j}^{\prime}+p=0 \\
\frac{\partial L}{\partial \gamma_{j}}=\alpha \bar{e}_{j}-\omega_{j} \geq 0 \\
\gamma_{j}\left(\alpha \bar{e}_{j}-\omega_{j}\right)=0, \quad \gamma_{j} \geq 0 .
\end{gathered}
$$

From Eq. (5) we conclude that the equilibrium carbon price equals to the marginal abatement cost $p\left(\omega^{*}\right)=C_{j}^{\prime}\left(q_{j}^{*}\right)$. Rewriting Eq. (4) leads to the following equilibrium condition:

$$
B_{j}^{\prime}-C_{j}^{\prime}=p^{\prime}\left(\omega^{*}\right)\left(\omega_{j}^{*}-\left(\bar{e}_{j}-q_{j}^{*}\right)\right)-\gamma_{j} .
$$

When the allowance choice constraint $\alpha \bar{e}_{j}$ is not binding, then the equilibrium conditions will be identical to the equilibrium condition for unconstrained carbon markets where the shadow value $\gamma_{j}=0$ in Eq. (8). This shows that with unconstrained allowance choices, the marginal revenues (either negative or positive) from carbon trade $p^{\prime}\left(\omega^{*}\right)\left(\omega_{j}^{*}-\left(\bar{e}_{j}-q_{j}^{*}\right)\right)$ are equal to the net marginal abatement benefits $B_{j}^{\prime}\left(q^{*}\right)-C_{j}^{\prime}\left(q_{j}^{*}\right)$. Compared to the unconstrained carbon markets, Eq. (8) shows that with constraints, each carbon trader's marginal abatement net benefits do not only depend on the marginal trade revenues 
$p^{\prime}\left(\omega^{*}\right)\left(\omega_{j}^{*}-\left(\bar{e}_{j}-q_{j}^{*}\right)\right)$, but are also affected by the shadow value of the allowance choices if the constraint is binding. With a constraint on allowance choices, the shadow value $\gamma_{j}$ represents the unavailable marginal gains due to the constraint on $j$ 's allowances. Substituting $C_{j}^{\prime}\left(q_{j}^{*}\right)$ with $p\left(\omega^{*}\right)$ in Eq. (8) we obtain the carbon price

$$
p\left(\omega^{*}\right)=B_{j}^{\prime}-p^{\prime}\left(\omega^{*}\right)\left(\omega_{j}^{*}-\left(\bar{e}_{j}-q_{j}^{*}\right)\right)+\gamma_{j}
$$

Eq. (9) implies that the carbon price will be impacted by the constraint. The more stringent the constraint is, the higher is the shadow price of allowances and the more valuable are emission allowances.

Now consider that the value of the constraint parameter $\alpha$ decreases such that the constraint is binding for all carbon traders and, hence, the optimal choice of initial allowances is $\omega_{j}^{*}=$ $\alpha \bar{e}_{j}$. Then the size of the market is $\omega^{*}=\alpha \sum_{j \in T} \bar{e}_{j}$. Any further decrease of $\alpha$ further reduces the optimal allowance choices $\omega_{j}^{*}$ and, hence, $\omega^{*}$. Reduced allowance choices require increased after-trade abatements $q_{j}^{*}=q_{j}^{*}\left(p\left(\omega^{*}\right)\right)$, higher marginal abatement cost and, since $p\left(\omega^{*}\right)=C_{j}^{\prime}\left(q_{j}^{*}\right)$, also the carbon price $p\left(\omega^{*}\right)$ is higher.

It is interesting to consider the implications of the Kuhn-Tucker condition $\frac{\partial \pi_{j}}{\partial \omega_{j}}-\gamma_{j}=0$; see Eq. (4), rewritten in (8). When the shadow value of allowances $\gamma_{j}=0$, the constraint is not binding and carbon traders $j(j \in T)$ will choose their optimal allowances as $\omega_{j}^{*}<\alpha \bar{e}_{j}$. Then the equilibrium condition will be identical to the equilibrium in an unconstrained carbon market. This can happen when the constraint is lax, especially to the carbon buyer regions with high marginal abatement benefits and costs. The numerical results shown in Table 3 confirm that carbon buyer regions like USA and Japan choose non-binding levels of allowances with a lenient constraint. However, when the constraint is strict enough, it will be binding such that the shadow value $\gamma_{j}>0$ in Eq. (8). If the allowance choice constraint is binding, traders $j(j \in T)$ choose their optimal allowances as $\omega_{j}^{*}=\alpha \bar{e}_{j}$. Since $\frac{\partial \pi_{j}}{\partial \omega_{j}}=\gamma_{j}>0$, it can be concluded that the gains of all carbon traders decrease with the tightening of the constraint on allowance choices. Consequently, the participation incentives decrease and thus there is no carbon market when the constraint is too strict. In this case the internal stability condition, specified below, is violated.

Finally, to conclude the analysis of stage 2, we still need to consider the behaviour of the singletons. As they cannot participate in the market, they decide their mitigation levels by maximising the payoffs specified in Eq. (2). Their best response is characterised by $C_{j}^{\prime}\left(q_{j}^{*}\right)=B_{j}^{\prime}\left(q^{*}\right)$.

\section{Stage 1: Membership choice}

At stage 1, all players make their membership decisions considering how the stage- 2 game will be played. The Nash equilibria of the membership game correspond to cartel stability (d'Aspremont et al. 1983; Barrett 1994). Hence, in an equilibrium carbon market satisfying internal and external stability, no trade participant has an incentive to leave and no singleton has an incentive to participate; see conditions (10) and (11) below. For a carbon market $T$ with constraint parameter $\alpha$, we introduce a partition function $V_{j}(T ; \alpha)$ to represent the payoffs of trade participants $j(j \in T)$ and singletons $j(j \notin T)$ as a function of the set of traders. An equilibrium carbon market is formed if the following internal and external stability conditions hold: 


$$
\begin{aligned}
& \text { Internal stability: } V_{j}(T ; \alpha) \geq V_{j}(T \backslash\{j\} ; \alpha), \quad j \in T, \\
& \text { External stability: } V_{j}(T ; \alpha) \geq V_{j}(T \cup\{j\} ; \alpha), \quad j \notin T .
\end{aligned}
$$

\section{Simulation analysis and results}

To illustrate the consequences of imposing constraints on individual allowance choices for the stability and the performance of an international carbon market, we conduct a simulation analysis based on our two-stage game employing the STACO model. A detailed description of the numerical approach is presented in Sect. 4.1. To compare and analyse the differences in terms of stability and performance of international carbon markets with and without allowance choice constraints, we firstly examine the base scenario of an unconstrained carbon market. Results are provided in Sect. 4.2. The results for constrained carbon markets are presented and discussed in Sect. 4.3. In Sect. 4.4 as a sensitivity analysis, we provide results for a scenario where the non-cooperative Nash equilibrium emissions are used as a baseline for the allowances constraint.

\subsection{Simulations employing the STACO model}

Our simulation is performed by employing the STACO model, which is an integrated assessment model connecting GHG emissions with abatement costs and economic evaluations of climate damages for twelve different world regions: United States (USA), Japan (JPN), European Union-27 \& EFTA (EUR), Other High Income countries (OHI), Rest of Europe (ROE), Russia (RUS), High Income Asian countries (HIA), China (CHN), India (IND), the Middle East countries (MES), Brazil (BRA) and Rest of the World (ROW). In STACO, the economic evaluation with respect to the payoff assessment is specified by the comparison between abatement costs and benefits. Focusing on the establishment of an international carbon market, we modify carbon traders' payoff functions by including the carbon trade effects into the original payoff function in STACO under different constraints on allowance choices, as shown in Eq. (1). Considering inertia and the long term effects in the climate system, the STACO model evaluates GHG emission mitigation with projected baseline emissions $\bar{e}_{j}$ for a horizon of 100 years. Given the participation choice in the initial period, each region determines optimal abatement levels $q_{j}^{*}$ strategically in every time period. For a full specification of the latest version of the STACO model (STACO 3) the reader is referred to Nagashima et al. (2011) and Dellink et al. (2015).

We use the numerical computing software MATLAB to do the calculations and to derive the numerical solutions. The approach to solving the numerical model is implemented in steps: Firstly, we assign a number to all possible non-trivial carbon markets $(|T| \geq 2)$. With 12 regions, the total number of non-trivial carbon markets is $2^{12}-12$. In the second step, we calculate the equilibrium allowance choices, after-trade abatement and payoffs of each trader and for every possible market. We also calculate abatement levels of the singletons. Then we repeat this step for a tighter constraint on allowance choices, i.e. we lower the value of $\alpha$ stepwise (with step size $\Delta \alpha=0.02$ ) from 1 to the percentage of the social optimum emissions. From these results, we can observe the changes in abatement and payoffs of all players associated with different constraints. Based on the results from the second step, the equilibrium carbon markets can be identified and internal and external stability can be checked. Finally, from the performances and stability of the equilibrium carbon markets, we can identify an optimal exogenous constraint. 


\subsection{Results for carbon markets with unconstrained allowance choices}

In an unconstrained carbon market the initial emission allowances can be chosen arbitrarily by trade participants. We first look at the stability of all possible non-trivial carbon markets. Our result shows that no equilibrium carbon market is simultaneously satisfying internal and external stability conditions under unconstrained allowance choices. However, if we only consider internal stability, then there are 36 internally stable carbon markets. The internally stable carbon markets are listed in Table 1, which reports the 12 best-performing carbon markets in terms of the global NPV (net present value) over 100 years. From the last column of Table 1, we can see that with arbitrary allowance choices, carbon market participation is attractive to all potential carbon sellers which are characterized by low marginal abatement benefits and low marginal abatement costs. Full stability is undermined by the incentives for singletons to join, i.e. external stability is violated. Specifically, regions with low marginal benefits (i.e. see Table 7 in Appendix) from global abatement are highly motivated to join, for example OHI, ROE, RUS, HIA, IND, MES, BRA and ROW. The underlying reason is that regions with lower marginal benefits from global abatement have less incentive to reduce their emissions, hence their main motivation to join a carbon market is seeking revenues from carbon sales. This finding indicates that it will be difficult to establish an unconstrained carbon market under open membership. A constraint on the allowance choices could limit the participation incentives that are arising from revenue seeking behaviour which, in turn, results in hot air. A constraint on allowance choices may improve external stability.

Table 1 shows that global mitigation and welfare of the internally stable carbon markets are higher compared to the non-cooperative Nash equilibrium, but are much lower than the levels in the social optimum (see the first and second row of Table 1). This can be attributed to non-cooperative strategies of abatement choice and limited participation. As we can see from the second to the last row of Table 1 the global payoffs and abatement levels achieved under carbon trade are significantly higher than the no-trade Nash equilibrium. The welfare enhancement through carbon trade is mainly due to the cost-savings from cheaper abatement options. Exploiting cheaper abatement options increases global mitigation. Regions with high marginal abatement costs (MAC) (see Fig. 2 in Appendix) like JPN and EUR are motivated to abate more than their Nash equilibrium levels because of their higher shares of global abatement benefits. At the same time, a region like $\mathrm{CHN}$ which sells carbon without producing hot-air also contributes to the global abatement compared to the no-trade outcome. Hence, with carbon trade, the global emission reductions are larger and cheaper than in the notrade Nash equilibrium. Both traders and non-traders can benefit from the positive externality of the increased global mitigation.

The best-performing market is formed by two countries with different properties: EUR, which is characterized by high MAC, and CHN, which has the lowest MAC of all regions. In the best performing market, the MACs of the two traders are equalised at a carbon price of $4.74 \$ /$ ton $\mathrm{CO}_{2}$. This price is much lower than the MAC of EUR in the non-cooperative equilibrium and thus EUR benefits a lot from emission trading. In Carbone et al. (2009), the best market is also composed of EUR and CHN, which is comparable to our result. It is worth noticing the different carbon prices resulting in these different market structures as shown in column 4. Prices in the three best performing markets are higher than in other carbon markets. This is due to the number of participants with low MAC in the markets with a better performance. It is obvious that the carbon markets with lower carbon prices like $\{\mathrm{JPN}, \mathrm{CHN}$, IND $\}$ and $\{E U R, C H N, I N D\}$ are formed by more regions with low MAC compared to the carbon markets like $\{$ EUR, $\mathrm{CHN}\}$ and $\{\mathrm{JPN}, \mathrm{CHN}\}$. 
As shown by Helm (2003) and Carbone et al. (2009), the arbitrary choice of emission allowances can cause hot air in unconstrained carbon markets. Our results also confirm the existence of the hot-air effect. Table 2 reports the hot air effects that we find in eight of the twelve best-performing carbon markets listed in Table 1. Only the four best performing carbon markets do not show hot air effects. As explained in Carbone et al. (2009), hot air is not an issue for China as it prefers to maintain a relatively higher carbon price by reducing allowances. Hence the markets where China is the only carbon seller do not show hot air effects. For the carbon market $\{$ JPN, CHN, IND $\}$ the allowances supply by the world's two biggest carbon sellers China and India can easily satisfy the small demand of Japan, without supplying an amount beyond their BAU emissions. So, also in this case hot air is avoided. Comparing hot-air and global abatements, see columns 1 and 2 in Table 2, we find that the abatement is inversely associated with the magnitude of hot-air. This observation carries over to global payoffs which are also inversely related to the magnitude of hot-air. These results underline the negative impact of hot-air on abatement and welfare. According to Helm (2003), it is possible that the total allowances chosen by all carbon traders exceed their non-cooperative emissions level under certain conditions. However, in our simulations total allowances of all carbon traders are lower than their non-cooperative emissions. This can be seen by comparing the no-trade Nash emissions level and the allowance choices in a carbon market in Table 2. The reason is that although some traders choose allowances above the BAU level, other traders (i.e. EUR and JPN) who have large marginal benefits of global abatement will choose lower allowances than their no-trade Nash emissions level to offset the negative influence of others' excessive allowance choices.

Table 2 shows that the hot air effects is largest in the carbon market \{EUR, CHN, BRA\}, caused by excessive allowance choice of BRA. The driving force is Brazil's high marginal abatement costs, so it has an incentive to drive down the carbon price by increasing the amount of emission allowances; at the same time, Brazil's marginal benefits are quite low (see Table 7 in Appendix) and, hence, its incentives to reduce emissions are limited. As shown in the third row in Table 2, our results confirm that ROE, consisting of mainly the former Soviet Union countries, is one of the largest sources of hot air. In addition to its low benefits share from global abatement, the slow economic growth also reduces ROE's demand for GHG emission allowances. The reason why MES produces hot air can be understood because it is the largest exporter of fossil fuels. MES seeks to decrease the carbon price and thus to increase the carbon demand which has a positive influence on fossil fuel exports. The hot air effects generated in other three carbon markets shown in Table 2 are caused by regions like HIA, OHI and IND respectively. The common reason for hot air created in these three markets is their relatively low benefits from global abatement (see Table 7 in Appendix) and high revenues from carbon sales.

In summary, our numerical analysis confirms the advantage of carbon markets in terms of global welfare and mitigation as compared to the no-trade Nash equilibrium. However, without a constraint on allowance choices it is difficult for a carbon market with open membership to satisfy external stability, because it is easily destabilized by market entrants who seek to raise revenues from carbon sale. The lower a region's marginal damages of GHG emissions, the more allowances will be chosen. Excessive allowance choices result in an inefficient carbon market.

\subsection{Results for carbon markets with constraints on allowance choices}

In this part, we focus on the numerical analysis of a carbon market with a constraint on the allowance choices. As described in Sect. 3, allowance choices are limited to a fraction $\alpha$ 


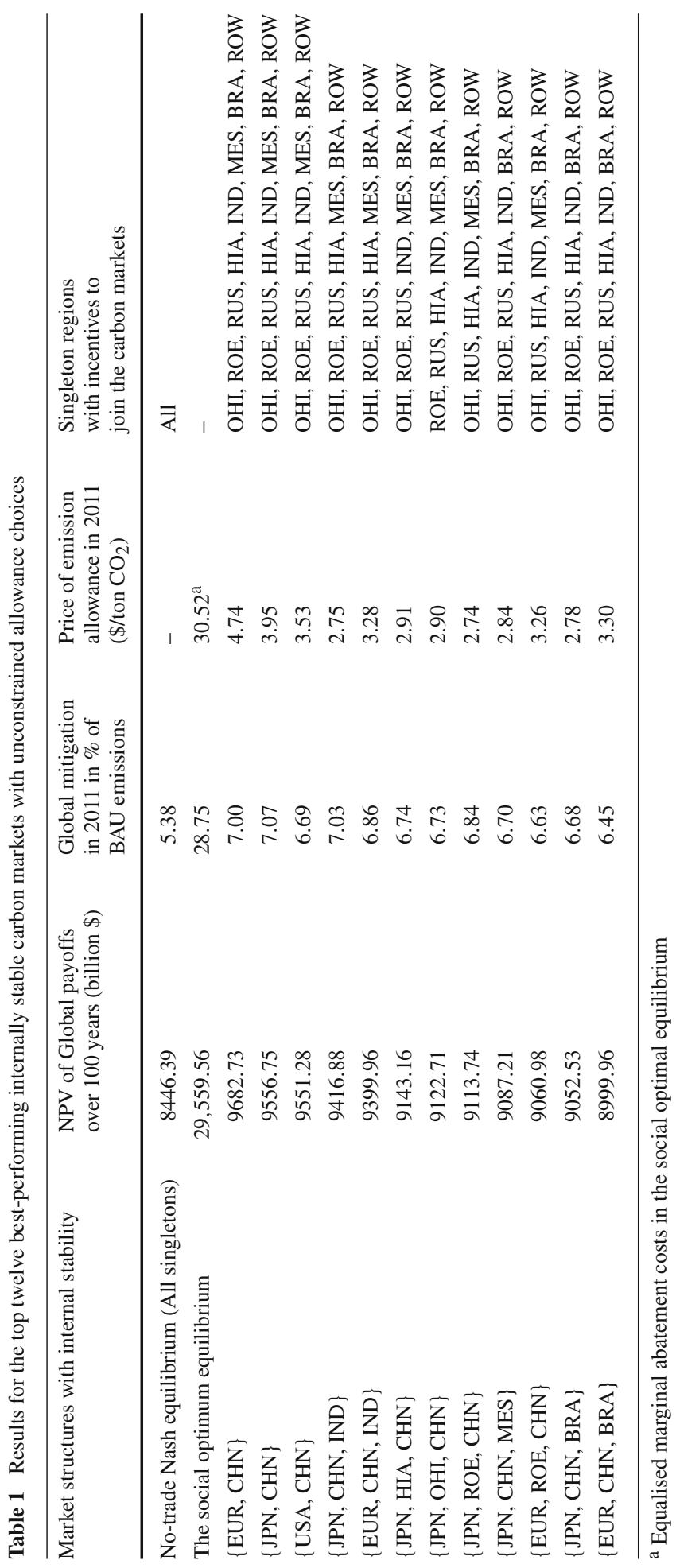




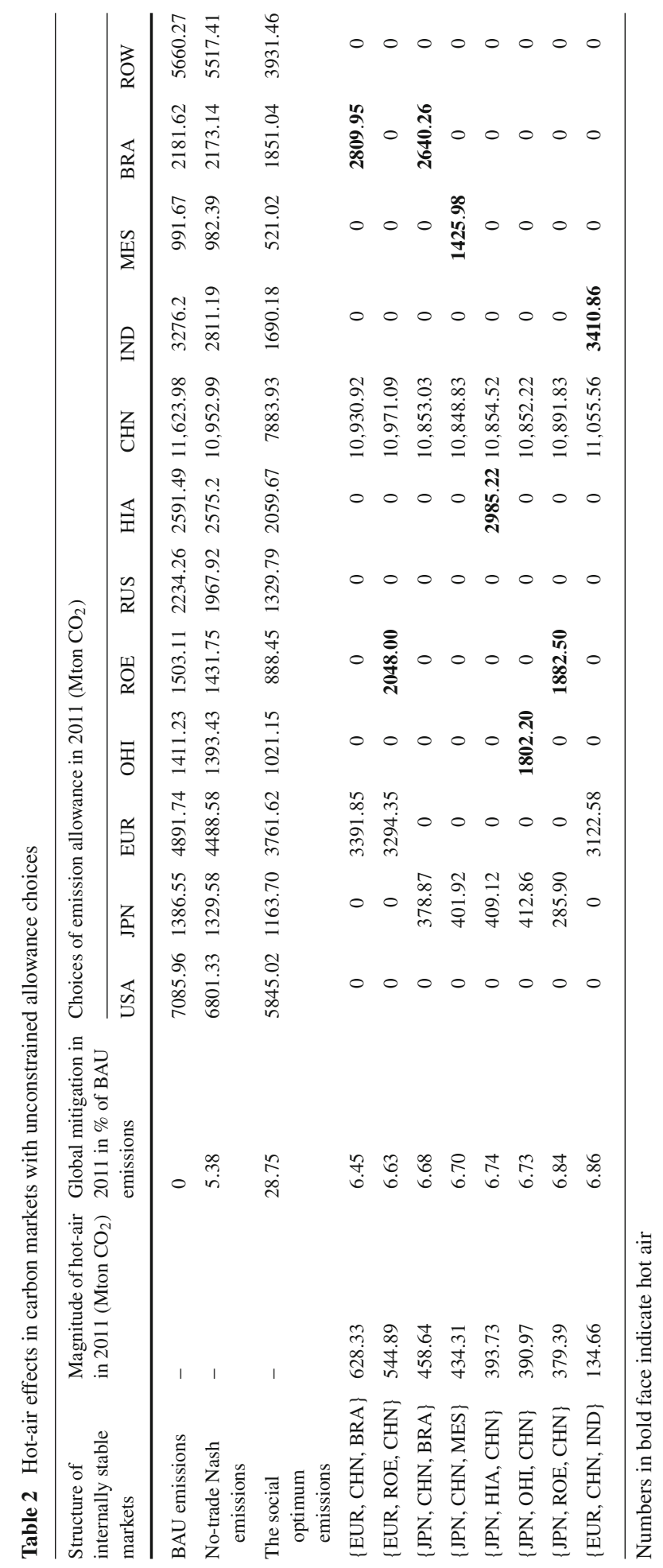


of each trade participant's BAU emissions. Table 3 reports the stable carbon markets that we find for different levels of $\alpha$. Compared to the unconstrained scenario, stability of and participation in the constrained carbon market are improved; with constraints we find 16 stable carbon markets and the maximum number of trade participants is increased to five (see last column of Table 3). As shown in Table 1, under unconstrained allowance choices, the potential carbon sellers have incentives to join (i.e. ROE, RUS, IND, BRA and ROW). With constraints on allowance choices, these singleton regions are discouraged to join the carbon trade and the degree of discouragement increases with the strictness of the constraints. From columns 1 and 4 of Table 3 we can see that when $\alpha$ falls from 0.98 to 0.88 , regions like ROE, RUS and IND are still willing to join; but when the value of $\alpha$ is decreased further, only RUS is motivated to join. Because ROE and IND are the main source of hot-air (as shown in Table 2), their marginal benefits from global abatement are much lower compared to Russia's (see marginal benefits in Table 7). When the constraint on allowance choices is too strict to make profits from selling carbon, ROE and IND prefer not to join the market. Table 3 shows that with a decrease of $\alpha$ from 0.84 to 0.74 , only the carbon market $\{$ JPN, RUS $\}$ still remains to be stable. This is because both JPN and RUS have incentives to reduce emissions through carbon trade due to relatively higher marginal abatement benefits, especially JPN. At the same time, even under a stricter constraint, JPN can still find cheaper abatement options from carbon trade, while RUS also can earn revenues from selling carbon. However, no stable carbon market can be found when $\alpha$ is lower than 0.74 . Note that the social optimum requires that global emission would fall to $71 \%$ of BAU emissions; see Table 1.

Table 3 displays that a stable carbon market will be the largest (in terms of the number of traders) when the constraint is modest, e.g. $\alpha=0.9$ and 0.88 . Moreover, multiple equilibrium carbon markets can emerge under modest constraints, e.g. $\alpha=0.94,0.92$ and 0.88 . However, when the constraint becomes stricter, e.g. $\alpha<0.88$, the number of stable markets and their size decrease. The list of the equilibrium carbon markets under different constraints, shown in the last column of Table 3, also shows that when $\alpha<0.88$, the stability of the equilibrium carbon market $\{$ JPN, RUS $\}$ is robust to varying the allowance constraint. This robustness implies that for regions like JPN and RUS, the ranges of cost savings in abatement and earnings from carbon sale are so large that they can still benefit from carbon trade under more stringent constraints. It is interesting to observe the relationship between the actual allowance choices and the constraint. As shown in column 2 of Table 3, under less strict constraints, e.g. from $\alpha=0.98$ to 0.88 , the actual allowance choices of carbon buyers (i.e. USA and JPN) with higher marginal abatement benefits, are generally non-binding. Carbon sellers (i.e. IND, ROE and RUS) who have lower marginal benefits from global abatement but can raise revenues from carbon sale, prefer to choose allowances at the binding levels (shown by bold numbers in Table 3 ). However, when the constraint is becoming stricter, e.g. $\alpha<0.88$, it becomes binding for all traders.

Table 3 also shows that, a global market involving all world regions is difficult to realise. However, at least some larger GHG emitters like USA, IND and RUS can be included in a carbon trade agreement. The non-existence of a stable global carbon market indicates that the constraints imposed on the allowance choices can stabilise the carbon market to a certain degree but cannot completely overcome free-riding incentives. It is worth noting that $\mathrm{CHN}$ does not join any carbon market satisfying internal-external stability under different constraints, in contrast to the observation that $\mathrm{CHN}$ is part of the internally stable unconstrained markets discussed in the previous subsection. To see why this is the case notice that the markets listed in Table 1 are externally unstable because others would like to join, create hot air, and thus destabilise the (enlarged) market. Although hot air is ruled out in the constrained market, a similar mechanism is at work. Consider a lax constraint, e.g. $\alpha=0.98$. Here CHN 


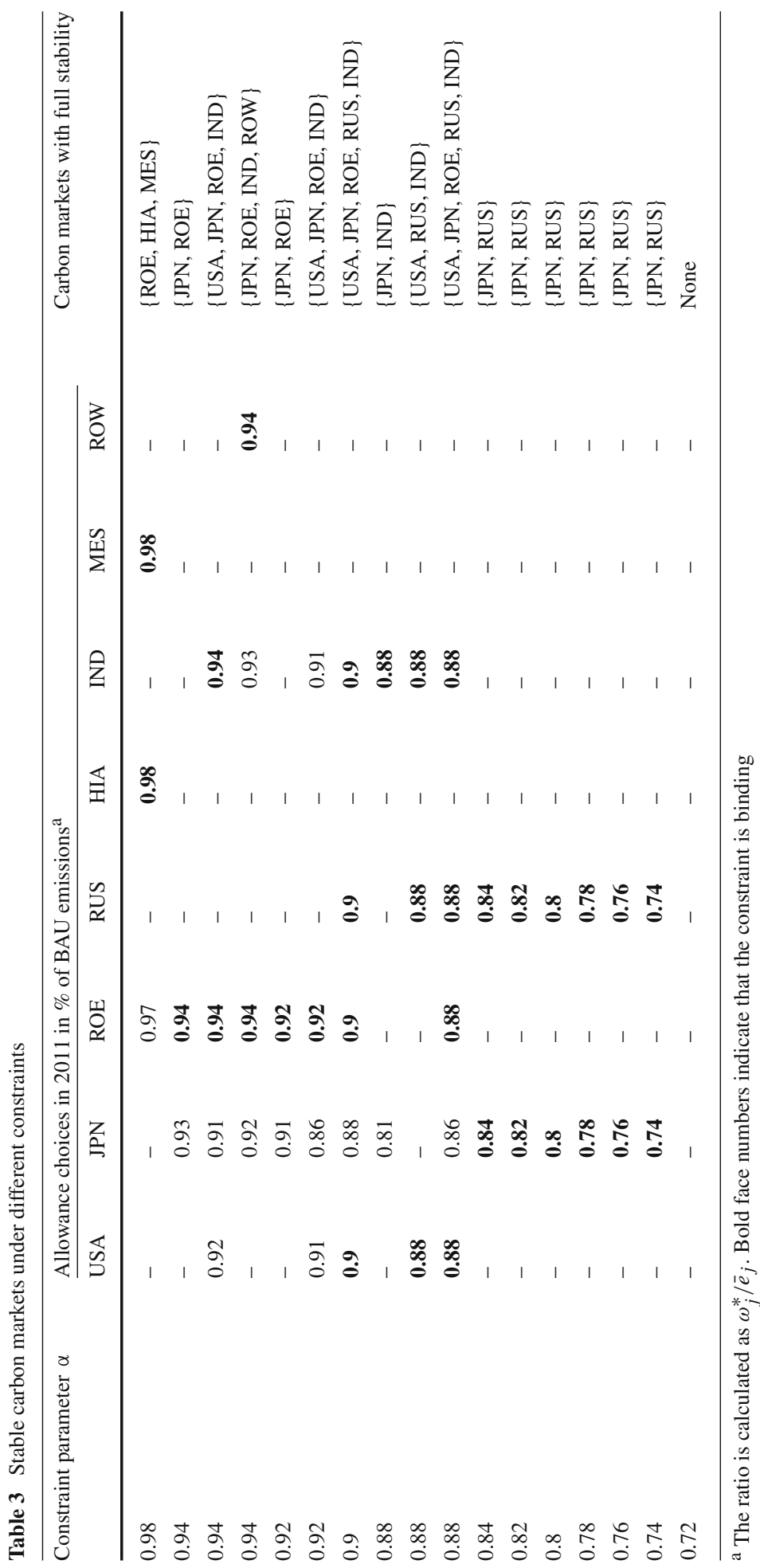


would not join $\{$ ROE, HIA, MES $\}$ because ROE would then increase allowances. For stricter constraints the reason for the absence of China is that market entry requires a tough restriction of allowances such that potential revenues from sales of allowances are overcompensated by higher abatement costs.

Table 4 reports performances of the equilibrium carbon markets in terms of global welfare and mitigation levels. From columns 4 and 5 of Table 4, we find that global welfare (NPV over 100 years) and mitigation of the carbon market are depending on the constraint. Figure 1a provides a scatter plot of the global NPV over 100 years achieved by the equilibrium carbon markets for different levels of the constraint. Note that at $\alpha=0.88,0.92$ and 0.94 we find multiple equilibrium carbon markets. The trend line in Figure 1a shows that the global NPV of the equilibrium carbon markets generally increases when the constraint becomes stricter. Similarly mitigation levels increase as the constraint becomes stricter. Turning to coalition structures we observe that when tightening the constraint 'broad but shallow' agreements are replaced by 'narrow but deep' ones. As the constraint becomes stricter it becomes binding for more traders and the shadow value of allowances increases. This indicates increasing forgone payoffs for individual coalition members. At the same time tougher abatement targets of the coalition increase the free-rider incentives and only a small coalition \{JPN, RUS $\}$ remains to be stable when the constraint tightens. Enhanced welfare effects resulting from more stringent policies can be explained as follows. Carbon sellers, due to the constraints on total emission allowances, have improved payoffs through an increased carbon price and abatement benefits which outweigh larger abatement costs. Carbon buyers who usually obtain higher marginal benefits of global abatement, can gain from the increased mitigation level. Lastly, singletons have higher payoffs from increased global mitigation. Figure $1 \mathrm{~b}$ shows the carbon price in equilibrium carbon markets under different constraints. We can see that the carbon price is generally higher when the constraint becomes tighter. Multiple prices that can be observed at $\alpha=0.88,0.92$ and 0.94 relate to the multiple equilibrium carbon markets (e.g. \{USA, JPN, ROE, RUS, IND $\},\{$ USA, RUS, IND $\}$ and $\{$ JPN, IND $\}$ at $\alpha=0.88$ ).

The first row of Table 4 shows the best-performing stable carbon market is formed by \{USA, JPN, ROE, RUS, IND $\}$ under $\alpha=0.88$. This market has the largest membership and the highest mitigation level. A further tightening of the constraint would further increase mitigation and welfare for the given coalition, however, it will destabilise the coalition since free-rider incentives are stronger under a stricter constraint.

In order to gain better insights into the performance of the equilibrium carbon markets under constraints, we report more details of the best-performing carbon market \{USA, JPN, ROE, RUS, IND $\}$ under $\alpha=0.88$ in Table 5. Column 2 shows that all equilibrium allowance choices are bound by the constraint except for JPN. This is because JPN has the highest marginal benefits from global abatement such that JPN prefers to maintain a high global abatement. This result can also be explained by the shadow value of allowances shown in column 4 of Table 5, which indicate that JPN would not lose from a marginal tightening of the allowance constraint. These indicate for all traders except JPN that relaxing the constraint for an individual trader will benefit that trader. Concerning the after-trade abatement the carbon buyers USA and JPN, having the highest MAC, will abate less than their non-cooperative levels (shown in Appendix Table 8) since they can buy cheap allowances. However the sellers (i.e. ROE, RUS and IND) having lower MAC almost double abatement compared with their non-cooperative abatement levels. The singletons choose the same abatement levels as in the no-trade Nash equilibrium, since they have dominant strategies in the abatement game. Due to increased abatement through carbon trade, the payoffs of all regions are improved as compared to the Nash payoffs (shown in the Appendix, Table 8). 


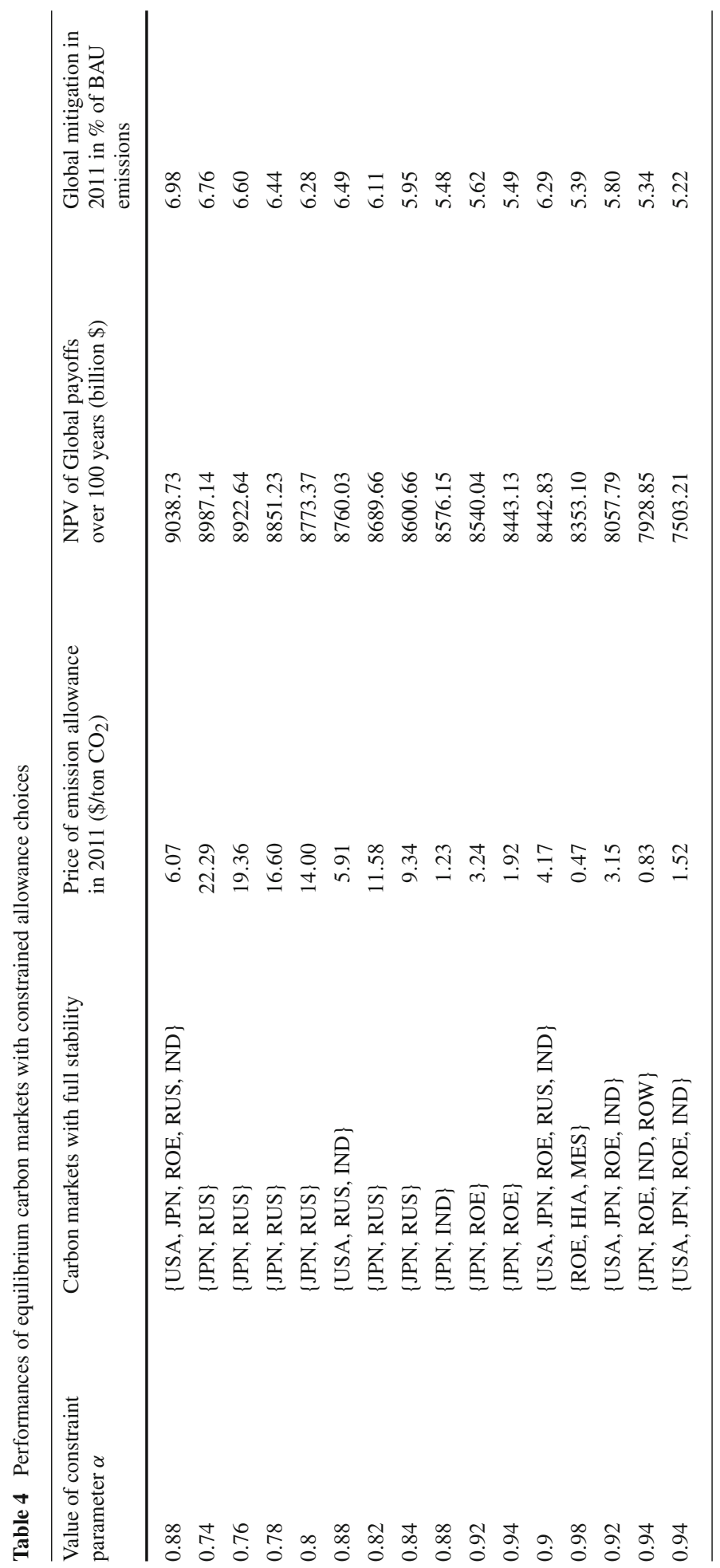



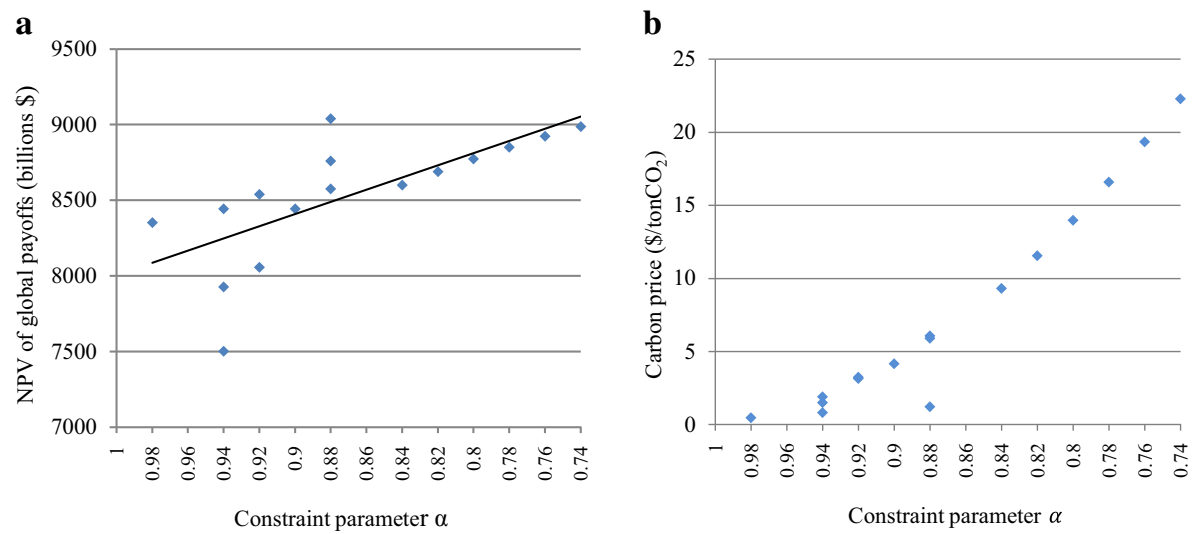

Fig. 1 a Global NPV of the equilibrium carbon markets under different constraints. b Carbon price in the equilibrium carbon markets under different constraints

Overall, our numerical results confirm the cost effectiveness and environmental effectiveness of carbon trade, compared to the no-trade Nash equilibrium. However, in a carbon market with unconstrained allowance choices, the incentive of earning revenues from carbon sales and the arbitrary allowance choices result in a hot-air effect and the external instability of a carbon market with open membership. When imposing constraints on allowance choices, the hot-air effect can be eliminated. Most importantly, by curbing the incentives of obtaining revenues from carbon sale through limiting the allowance choices, the external instability can be reduced. We also find that under a carbon market with constrained allowance choices global mitigation and welfare can be improved most when the constraint is moderate.

\subsection{Results for carbon markets with Nash-emission levels as baseline for allowance choice constraints}

In this chapter we examine the impact of the setting of the baseline on the stability and effectiveness of constrained carbon markets. In the following we assume that allowance constrains are based on non-cooperative Nash emissions levels, i.e. emissions in the All singletons case. Numerical results for all stable carbon markets under the constraint $\alpha \in[0,1]$ are reported in Table 6. In general, compared to the BAU baseline for the constraint, results indicate the possibility of larger stable coalitions and more effective markets, i.e. higher global abatement levels in equilibrium. Several features of this result are worth to be highlighted. Firstly, a global carbon market can be sustained when $\alpha=1$. In this grand carbon market where the upper bound of individual allowance choices is the Nash-emissions level, the global mitigation $(5.38 \%$ ) is equal to the All singletons structure (see column 5 of Table 6; compare to column 3 of Table 1). This result stems from the fact that individual allowance choices of all carbon traders are binding. In this case cooperation does not increase abatement but global payoffs are improved through carbon trade. When the constraint is tighter, at $\alpha=0.98$ and 0.96, partial carbon markets are stable that comprise of 11 and 8 regions, respectively. The highest global payoffs $(10,163.68$ billion $\$$ ) can be obtained when $\alpha=0.98$ and the highest global abatement level $(7.27 \%)$ can be achieved when $\alpha=0.96$. These results improve upon global welfare and abatement that can be achieved under the BAU baseline. 


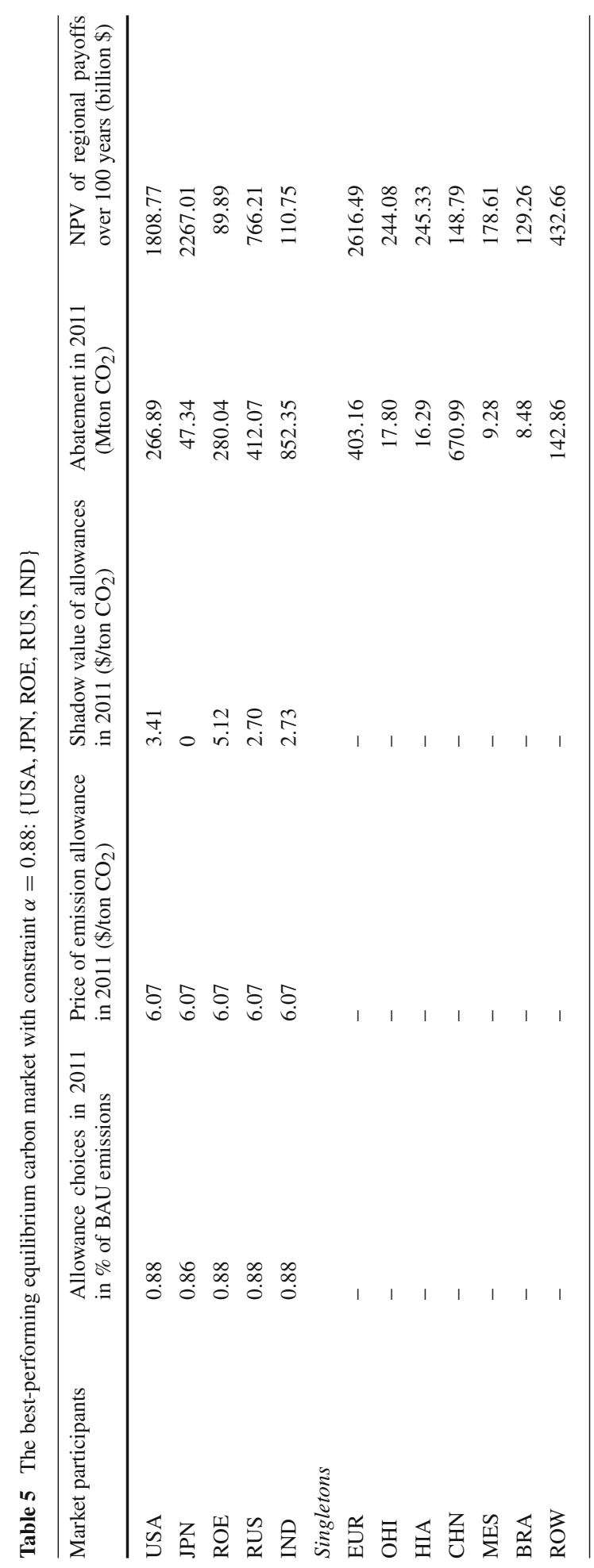




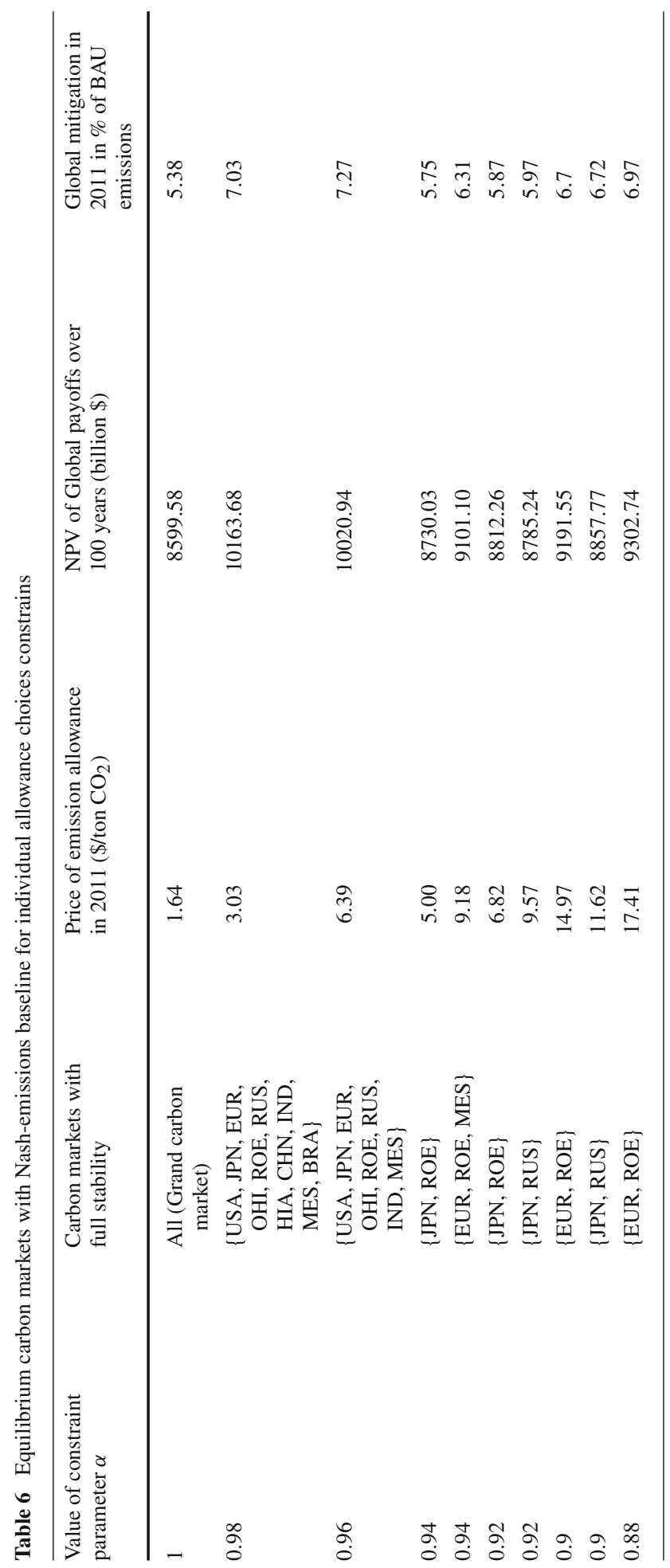


The enhanced stability and effectiveness of stable carbon markets with Nash baseline compared to the BAU baseline are related to the binding allowance choices of all carbon traders, which are found in all carbon markets from our numerical results. In particular, when $\alpha=1$, each region can only improve upon its Nash payoff by joining the carbon market. Thus a carbon market with full participation can be sustained. If the constraint is a little tighter, $\alpha=0.98$, only ROW prefers to take a free rider position. As argued before, tightening the constraint will always decrease the incentive to sign the agreement. Further tightening of the constraints causes more regions to drop out. From Table 6, it can be observed the size of stable carbon markets becomes smaller because of the increased free-riding incentives when the constraint becomes stricter. This is a general finding and robust to changes of the baseline.

\section{Conclusions}

In this paper, we focus on the conditions for developing a stable international carbon market. Without constraints on individual allowance choices a carbon market can suffer from hotair effects and market instability. To solve this problem, we consider the role of setting a constraint on allowance choices. Our main findings are the following.

First, under a carbon market with unconstrained allowance choices we find that no stable market emerges. Unconstrained allowance choices can cause hot-air and thus undermine effectiveness and stability of a carbon market.

Second, the stability and the membership of an international carbon market can be increased by imposing a constraint on allowance choices. The reason is that constrained allowance choices discourage excessive participation of potential sellers. This reduces or avoids hot air. Due to a constraint on the allowance choices, a higher global abatement level can be obtained. Generally, compared to an unconstrained market, constraints can improve the stability and enlarge the scale of an international carbon market, but only to a limited degree. The largest part of the of the potential gains from cooperation remains unexploited.

Third, when tightening the constraint 'broad but shallow' agreements are replaced by 'narrow but deep' ones. In our setting with a constraint on BAU emissions the carbon market with the largest membership can be formed under a relatively lax constraint (12\% below BAU emissions in the STACO calibration). When the constraint is closer to the globally optimal abatement, we observe a narrower but deeper stable market with similar performance in terms of global abatement and welfare. We also find that under lax constraints, carbon buyers generally choose their allowances strictly lower than their constraint while sellers choose the binding level. Stricter constraints are binding for all traders. This result is not surprising since the strategic allowance choices by carbon buyers are motivated by the benefits from abatement, while carbon sellers are motivated mainly by revenues of carbon sales. These different motivations induce the strategic allowance choices to depend on the strictness of constraints.

Fourth, our results also point at an alternative option for stabilising an international carbon market. As external instability is an issue, limiting access will increase abatement and global welfare. In fact limiting access can be more effective than allowance choice constraints based on BAU emissions; compare the best performing markets in Tables 1 and 4. This is in line with the conclusion by Finus (2008) that an open membership regime adopted in current international climate negotiations should be critically reviewed. However this conclusion does not carry over to the case of constraints based on Nash emissions. 
Finally, we demonstrate that by tying individual allowance choice constraints to the Nashemissions levels, a carbon market with full participation can be sustained when the constraint is sufficiently lax (i.e. $\alpha$ close to 1). Different from BAU-related baselines, Nash-related baselines are always binding. Our result indicates that a Nash-related baseline is more successful in terms of global welfare and abatement, as it responds better to individual incentives to participate. In the current policy debate BAU emissions are still dominant for defining and negotiating abatement targets or emission allowances. Our finding suggests that a revision of the baseline could ease negotiations.

A limitation of our analysis is that the constraint on allowance choices is modelled as an exogenous parameter which is common for all carbon traders. A valuable extension of the model would be to include a pre-negotiation stage where the set of all regions first determines the constraint—possibly conditional on regional characteristics—and only after that the membership and allowance choices would follow.

Acknowledgements We wish to thank two anonymous reviewers for helpful comments. We are grateful to Rob Dellink and Miyuki Nagashima who have supported our numerical analysis. The first author acknowledges support by the Erasmus Mundus EURASIA 2 (www.eurasia2.cz) programme.

Open Access This article is distributed under the terms of the Creative Commons Attribution 4.0 International License (http://creativecommons.org/licenses/by/4.0/), which permits unrestricted use, distribution, and reproduction in any medium, provided you give appropriate credit to the original author(s) and the source, provide a link to the Creative Commons license, and indicate if changes were made.

\section{Appendix}

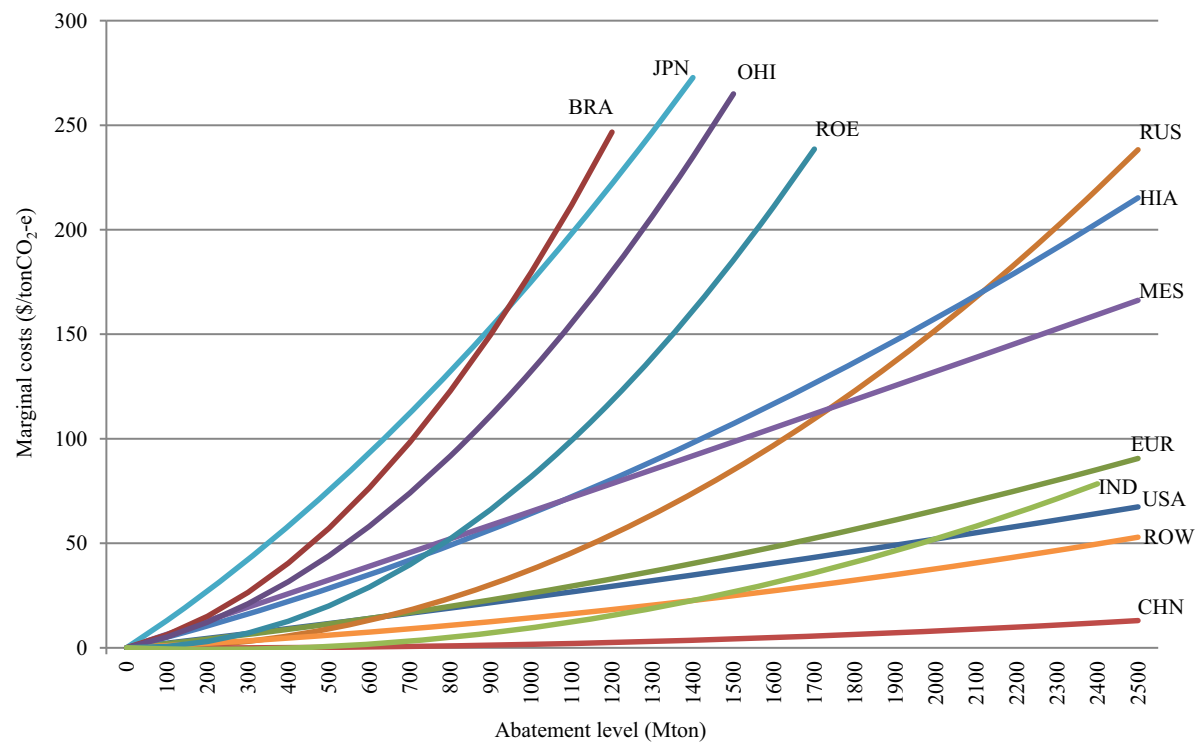

Fig. 2 Marginal abatement cost curves in 2011 in the STACO model 
Table 7 Benefits share, marginal benefits and BAU emissions in the STACO model

\begin{tabular}{lllc}
\hline Regions & $\begin{array}{l}\text { Benefits share of } \\
\text { global abatement }\end{array}$ & $\begin{array}{l}\text { Marginal benefits in } \\
2011\left(\$ / \text { ton } \mathrm{CO}_{2}\right)\end{array}$ & $\begin{array}{l}\text { Uncontrolled Emis- } \\
\text { sions }(\mathrm{BAU}) \text { in 2011 } \\
\left(\mathrm{Gton} \mathrm{CO}_{2}\right)\end{array}$ \\
\hline USA & 0.2265 & 6.49 & 7084.96 \\
JPN & 0.1725 & 7.34 & 1386.55 \\
EUR & 0.2360 & 8.92 & 4891.74 \\
OHI & 0.0345 & 0.80 & 1411.23 \\
ROE & 0.0130 & 0.30 & 1503.11 \\
RUS & 0.0675 & 2.43 & 2234.26 \\
HIA & 0.0300 & 0.81 & 2591.49 \\
CHN & 0.0620 & 0.57 & 11623.98 \\
IND & 0.0500 & 0.34 & 3276.20 \\
MES & 0.0249 & 0.60 & 991.67 \\
BRA & 0.0153 & 0.43 & 2181.62 \\
ROW & 0.0680 & 1.49 & 5660.27 \\
Sum & 1.0000 & - & 44837.08 \\
\hline
\end{tabular}

Table 8 Performances of the non-cooperative Nash equilibrium and the first-best social optimum scenario

\begin{tabular}{lccccc}
\hline Regions & Nash equilibrium & & & \multicolumn{2}{l}{ Social optimum } \\
\cline { 2 - 3 } \cline { 5 - 6 } & $\begin{array}{l}\text { Abatement in 2011 } \\
\left(\text { Mton } \mathrm{CO}_{2}\right)\end{array}$ & $\begin{array}{l}\text { NPV of payoffs over } \\
\text { 100 years (billion \$) }\end{array}$ & $\begin{array}{l}\text { Abatement in } \\
2011\left(\text { Mton } \mathrm{CO}_{2}\right)\end{array}$ & $\begin{array}{l}\text { NPV of payoffs over } \\
\text { 100 years (billion \$) }\end{array}$ \\
\hline USA & 284.63 & 1742.81 & 1240.94 & 6558.90 \\
JPN & 56.97 & 2125.91 & 222.85 & 9310.70 \\
EUR & 403.16 & 2428.74 & 1130.12 & 10128.17 \\
OHI & 17.80 & 228.31 & 390.08 & 707.83 \\
ROE & 71.36 & 85.83 & 614.66 & 19.26 \\
RUS & 266.34 & 686.37 & 904.47 & 2421.62 \\
HIA & 16.29 & 228.75 & 531.82 & 345.23 \\
CHN & 670.99 & 138.94 & 3740.05 & -727.20 \\
IND & 465.01 & 90.61 & 1586.02 & 0.88 \\
MES & 9.28 & 166.47 & 470.65 & 92.81 \\
BRA & 8.48 & 120.49 & 330.59 & 193.56 \\
ROW & 142.86 & 403.16 & 1728.81 & 507.82 \\
Global & 2413.17 & 8446.39 & 12891.06 & 29559.58 \\
\hline
\end{tabular}

\section{References}

Altamirano-Cabrera, J.-C., \& Finus, M. (2006). Permit trading and stability of international climate agreements. Journal of Applied Economics, IX(1), 19-47.

Barrett, S. (1994). Self-enforcing international environmental agreements. Oxford Economic Papers, 46, 878894.

Behr, T., Witte, J.-M., Hoxtell, W., \& Manzer, J. (2009). Towards a global carbon market? Potential and limits of carbon market integration. Berlin: Global Public Policy Institute (GPPI). 
Carbone, J. C., Helm, C., \& Rutherford, T. F. (2009). The case for international emission trade in the absence of cooperative climate policy. Journal of Environmental Economics and Management, 58, 266-280.

d'Aspremont, C., Jaquemin, A., Gabszewicz, J. J., \& Weymark, J. A. (1983). On the stability of collusive price leadership. Canadian Journal of Economics, 16(1), 17-25.

Dellink, R. B., de Bruin, K., Nagashima, M., van Ierland, E. C., Urbina-Alonso, Y., Weikard, H.-P., \& Yu, S. (2015). STACO Technical Document 3: Model description and calibration of STACO 3. Wageningen School of Social Sciences, Working Paper No. 12, Wageningen University.

Finus, M. (2008). Game theoretical research on the design of international environmental agreements: insights, critical remarks, and future challenges. International Review of Environmental and Resource Economics, 2, 29-67.

Flachsland, C., Marschinski, R., \& Edenhofer, O. (2009). To link or not to link: benefits and disadvantages of linking cap-and-trade systems. Climate Policy, 9(4), 358-372.

Helm, C. (2003). International emissions trading with endogenous allowance choices. Journal of Public Economics, 87, 2737-2747.

Nagashima, M., Weikard, H.-P., de Bruin, K., \& Dellink, R. (2011). International climate agreements under induced technological change. Metroeconomica, 62(4), 612-634.

Rehdanz, K., \& Tol, R. S. J. (2005). Unilateral regulation of bilateral trade in greenhouse gas emission permits. Ecological Economics, 54(4), 397-416.

Stavins, R. N., \& Jaffe, J. (2008). Linkage of tradable permit systems in international climate policy architecture. Nota di lavoro // Fondazione Eni Enrico Mattei: Sustainable development, No. 90.

Stern, N. (2008). The economics of climate change. American Economic Review, 98(2), 1-37.

Stevens, B., \& Rose, A. (2002). A dynamic analysis of the marketable permits approach to global warming policy: a comparison of spatial and temporal flexibility. Journal of Environmental Economics and Management, 44, 45-69.

UNFCCC (1998). Kyoto protocol to the United Nations Framework Convention on Climate Change. http:// unfccc.int/resource/docs/convkp/kpeng.pdf\#page=12. Accessed 2015. 